\title{
DETECÇÃO DE COLIFORMES EM AREIAS DE PRAIAS DE CARAGUATATUBA (SP)
}

Amanda Nunes Tenorio*

Dora Inés Kozusny-Andreani**

\begin{abstract}
RESUMO: As praias consistem em uma das principais atividades de lazer dos habitantes da cidades litorâneas. Nesse sentido, torna-se explícita a necessidade de manter a qualidade sanitária das praias, bem como seu entorno. O presente trabalho foi realizado com o objetivo de avaliar a presença de coliformes totais, termotolerantes e Escherichia coli na areia das principais praias do município de Caraguatatuba (SP) e testar a resistência a drogas antimicrobianas. As contagens de coliformes totais, termotolerantes e Esherichia coli foram realizadas pela técnica das diluições seriadas. Foram detectados coliformes totais e termotolerantes e Escherichia coli na areia de todas as praias avaliadas do Município de Caraguatatuba (SP). Concentrações elevadas foram detectadas nas praias Porto Novo, Centro, Martins de Sá, Indaiá e Cocanha. As cepas de E.coli isoladas das praias de Porto Novo, Centro, Indaiá, Cocanha e Tabatinga apresentaram resistência e multi resistência a alguns antimicrobianos testados.
\end{abstract}

PALAVRAS-CHAVE: Coliformes Termotolerantes; Coliformes Totais; Esherichia coli.

\section{COLIFORMS IN THE SAND IN BEACHES OF CARAGUATATUBA, BRAZIL}

ABSTRACT: Beeches are the sites of the main recreational activities of the inhabitants of coast cities and towns. It is obvious that their sanitary quality and of the environment should be also monitored and mandatory. Current study evaluates the presence of total and thermotolerant coliforms and Escherichia coli in the sand of the main beeches of Caraguatatuba SP Brazil and tests their resistance to antimicrobial drugs. Total and thermotolerant coliforms and Escherichia coli were counted by series dilution technique. Total and thermotolerant coliforms and Escherichia coli were detected in the sand of the beeches in Caraguatatuba. High concentration rates were also observed on the beeches called Porto Novo, Centro, Martins de Sá, Indaiá

\footnotetext{
Mestre em Ciências Ambientais pela Universidade Brasil.

** Docente Titular. Programa de Mestrado em Ciências Ambientais - Universidade Brasil, Campus Fernandópolis (SP), Brasil. E-mail: doraines@terra.com.br
} 
and Cocanha. E.coli strains, isolated from the beeches Porto Novo, Centro, Indaiá, Cocanha and Tabatinga, were resistant and multi-resistant to several antimicrobials tested.

KEY WORDS: Thermotolerant coliforms; Total coliforms; Esherichia coli.

\section{INTRODUÇÃO}

A qualidade ambiental das praias tem adquirido uma importância crescente por razões ambientais e de saúde pública. Atualmente, os indicadores de qualidade disponíveis que geralmente permitem uma avaliação por parte da população quanto às condições de banho são os índices de coliformes fecais na água. As areias são, no entanto, uma possível fonte de contágio de micro-organismos patogênicos.

A presença de patógenos, tanto na areia, quanto na água, consiste em uma ameaça à saúde da população e banhistas que podem estar sujeitos a doenças causadas por vírus, bactérias e fungos (VELONAKIS et al., 2014). Nos últimos anos foi verificado um aumento dos casos de micoses e infecções bacterianas contraídas por pessoas que frequentam as praias e utilizam suas areias como local de recreação. Isso tem ocasionado maiores preocupações com a contaminação microbiana (PINTO; OLIVEIRA, 2011).

A balneabilidade das praias está relacionada geralmente à qualidade microbiológica da água. No entanto, a preocupação com a contaminação da areia da praia tem aumentado nos últimos anos devido à disposição inadequada de lixo, resíduos animais, esgotos domésticos sem tratamento e poluição que são levados pela água da chuva (VALDEZ; GROSBELLI, 2012; ANDRAUS et al., 2014).

Há evidências de que bactérias patogênicas sobrevivem em areias, pois estas recebem poluentes de diferentes fontes. Além disso, fatores abióticos favoráveis, tais como temperatura, umidade, $\mathrm{pH}$, matéria orgânica, entre outros, favorecem o fenômeno de bioacumulação (ABDALLA et al., 2005; ELMANAMA et al., 2005). As águas podem ser influenciadas por populações persistentes destas bactérias em areias ou esgotos locais, além de entradas variadas de origem humana fecal ou animal (HALLIDAY et al., 2014), e a qualidade sanitária da água de balneários é avaliada pela presença de bactérias cultiváveis fecais indicadoras. 
A detecção e a quantificação de indicadores em areias recreacionais são de grande importância para verificar o risco da presença de micro-organismos patogênicos nesse ambiente. As agências reguladoras encarregadas de monitorar águas recreacionais utilizam como base bactérias indicadoras de contaminaçào fecal (FIB), tais como Escherichia coli e enterococos porque estudos epidemiológicos demonstraram que concentrações de FIB em águas de recreio impactadas por efluentes de estações de tratamento (ou seja, fontes pontuais de esgoto sanitário) foram correlacionados com doenças adquiridas em áreas de recreação (SHIBATA; SOLO-GABRIELE, 2012).

Segundo a Companhia de Tecnologia de Saneamento Ambiental (CETESB, 2008), são definidos como micro-organismos do grupo coliforme aqueles capazes de fermentar a lactose a $44-45^{\circ} \mathrm{C}$, sendo representados principalmente por Escherichia coli e também por algumas bactérias dos gêneros Klebsiella, Enterobacter e Citrobacter. Dentre esses micro-organismos, somente a $E$. coli é de origem exclusivamente fecal, estando sempre presente em densidades elevadas nas fezes de humanos, mamíferos e pássaros, sendo raramente encontrada na água ou solo que não tenham recebido contaminação fecal. Os demais podem ocorrer em águas com altos teores de matéria orgânica, como, por exemplo, efluentes industriais, ou em material vegetal e solo em processo de decomposição.

Haja vista que o número de coliformes termotolerantes presentes nas fezes do homem e animais de sangue quente, sua presença na areia da praia, constitui um caso de saúde pública, necessitando assim de estudos aprofundados (CARDOSO-DE-OLIVEIRA; PINHATA, 2008). Neste contexto o presente trabalho teve como o objetivo avaliar a presença de coliformes na areia das principais praias do Município de Caraguatatuba (SP) e determinar a resistência destas bactérias às drogas antimicrobianas.

\section{MATERIAL E MÉTODOS}

A área de estudo compreendeu o município de Caraguatatuba (SP), com latitude $23^{\circ} 37^{\prime} 13^{\prime \prime} \mathrm{S}$ e longitude $45^{\circ} 24^{\prime} 47^{\prime \prime} \mathrm{W}$. Foram selecionadas sete praias con- 
sideradas de alta afluência de público e preferidas por turistas. As praias foram identificadas por letras (Figura 1), sendo A: praia do Porto Novo, B: praia do Indaiá, C: praia do Centro, D: Prainha, E: praia Martim de Sá, F: praia da Cocanha, G: praia da Tabatinga.

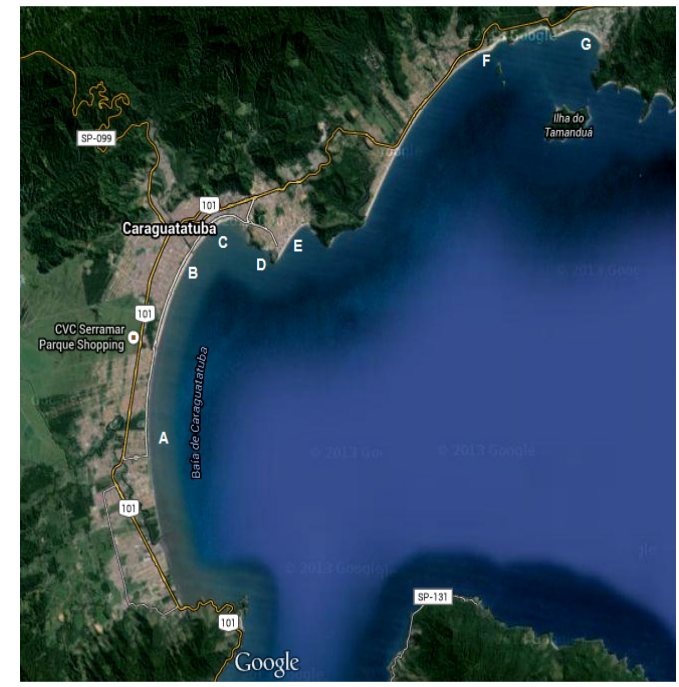

Figura X: Pontos de coleta na orla de Caraguatatuba: A - Praia do Porto Novo; B - Praia do Indaiá; C - Praia do Centro; D - Prainha; E - Praia Martins de Sá ; F - Praia Cocanha; G - Praia Tabatinga - fonte: google maps 2015 (adaptado)

Figura 1. Localizaçao dos pontos de coleta de areia das praias de Caraguatatuba (SP). A: praia do Porto Novo, B: praia do Indaiá, C: praia do Centro, D: Prainha, E: praia Martim de Sá, F: praia da Cocanha, G: praia da Tabatinga.

Fonte: Google Maps (adaptado pelos autores).

As praias foram escolhidas pela preferência de turistas e moradores locais. Os pontos de coleta foram determinados pelo maior fluxo de pessoas do dia. A coleta de amostras de areia das praias para realização da pesquisa foi autorizada pela Secretaria de Turismo do Município de Caraguatatuba (SP). De cada praia foram coletadas três amostras de lugares diferentes no mesmo dia e em um intervalo de tempo entre a primeira coleta e a última no período das $08 \mathrm{~h}$ às $10 \mathrm{~h} 30$, totalizando vinte e uma amostras de areia. Para cada praia foram definidos os pontos de coleta: 
1) como mais próximo da água; 2) como intermediário entre a areia e a costa; e 3) mais próximo da costa. Cada amostra consistiu em $200 \mathrm{~g}$ de areia superfícial recolhida a uma profundidade máxima de $5 \mathrm{~cm}$, usando uma espátula esterilizada, em cada amostragem. O material foi transferido para recipientes estéreis, transportados para o laboratório em caixa isotérmica, contendo gelo. A amostragem foi realizada em abril de 2015, sendo assim considerada pela Secretaria de Turismo uma época de baixa temporada.

As análises microbiológicas foram realizadas pelos métodos baseados na técnica de diluições seriadas (EATON; FRANSON, 2005). As amostras de areia foram preparadas adicionando-se $10 \mathrm{~g}$ de areia em $90 \mathrm{~mL}$ de solução salina estéril ( $\mathrm{NaCl}$ $0,85 \%$ ), contida em frascos estéreis com tampa, na sequência foram agitados por 30 minutos em mesa orbital (200 rpm). O líquido superior foi coletado para ser utilizado como a solução inicial, a partir da qual foram realizadas diluições seriadas.

Alíquotas de $1 \mathrm{~mL}$ das diluições seriadas de $10^{-1}$ a $10^{-4}$ foram inoculadas nos meios de cultivo Caldo Lactosado e Esherichia coli (EC) contendo um tubo de Durhan invertido, usando-se séries de 3 tubos para cada diluição, incubados por 24-48 horas a $37^{\circ} \mathrm{C}$ e obtidos os resultados a partir de cada conjunto de tubos da mesma diluição. Os tubos positivos para caldo lactosado foram inoculados em Caldo Lactose Bile, Verde Brilhante (VB) e incubados a $37{ }^{\circ} \mathrm{C}$ para detecção de coliformes totais.

Para análise de coliformes termotolerantes foi usado Caldo EC incubado a $45^{\circ} \mathrm{C}$ por $24-48$ horas. De cada tubo de Caldo EC positivo, foi retirada uma alçada do meio e estriada em placas contendo Ágar MacConkey Sorbitol e ágar Eosina-Azul de metileno (EMB), incubadas a $37^{\circ} \mathrm{C}$ por $24-48$ horas, para verificar o crescimento de colônias típicas de Escherichia coli. Para confirmação de E.coli foi utilizado o Sistema API20E.

Os micro-organismos isolados foram expressos em unidades formadoras de colônias (UFC) por grama de areia.

Para avaliação da susceptibilidade antimicrobiana in vitro, se utilizou o método de Kirby Bauer Modificado (CLSI, 2013), e foram avaliados os antimicrobianos amicacina $(30 \mu \mathrm{g})$, Ampicilina $(10 \mu \mathrm{g})$, Aztreonam $(15 \mu \mathrm{g})$, Cefaclor $(30 \mu \mathrm{g})$, Cefazolina $(30 \mu \mathrm{g})$, Cefalexina $(30 \mu \mathrm{g})$, Cefalotina $(30 \mu \mathrm{g})$, Cefotaxime $(30 \mu \mathrm{g})$, Cefepime 
$(30 \mu \mathrm{g})$, Ceftazidima $(30 \mu \mathrm{g})$, Ceftriaxona $(30 \mu \mathrm{g})$, Ciprofloxacina $(5 \mu \mathrm{g})$, Clindamicina $(2 \mu \mathrm{g})$, Cloranfenicol $(30 \mu \mathrm{g})$ e Tetraciclina $(30 \mu \mathrm{g})$. Os resultados foram interpretados de acordo aos parâmetros estabelecidos pela CLSI (2013).

$\mathrm{O}$ índice de resistência múltipla aos antimicrobianos (IRMA) foi calculado conforme a metodologia descrita por Krumperman (1983). O IRMA foi calculado pela razão entre o número de antibióticos aos quais o isolado foi resistente e o número de antibióticos ao qual o isolado foi exposto. Quando o IRMA foi superior a 0,2 caracterizou multirresistência.

\section{RESULTADOS E DISCUSSÃO}

$\mathrm{Na}$ Tabela 1 estão apresentados os resultados obtidos do cultivo de areia de sete principais praias do município de Craguatatuba (SP). Constatou-se que dos vinte e um locais amostrados somente dois não apresentaram contaminação por coliformes, e corresponderam a Prainha.

Tabela 1. Concentração de coliformes totais, coliformes termotolerantes e Escherichia coli isolados de areia de praias do município de Caraguatuba (SP)

\begin{tabular}{lccccc}
\hline \multirow{2}{*}{ Praias } & $\begin{array}{c}\text { Número } \\
\text { de locais } \\
\text { amostrados }\end{array}$ & $\begin{array}{c}\text { Amostras } \\
\text { positivas (\%) }\end{array}$ & $\begin{array}{c}\text { Coliformes } \\
\text { totais }\end{array}$ & $\begin{array}{c}\text { Coliformes } \\
\text { termotolerantes }\end{array}$ & E. coli \\
\hline Prainha & 3 & 33,33 & $1,2 \times 10^{2}$ & $0,5 \times 10^{2}$ & $0,5 \times 10^{1}$ \\
Porto Novo & 3 & 100 & $1,6 \times 10^{5}$ & $1,0 \times 10^{3}$ & $0,2 \times 10^{3}$ \\
Martins de Sá & 3 & 100 & $2,0 \times 10^{3}$ & $0,4 \times 10^{4}$ & $1,0 \times 10^{3}$ \\
Centro & 3 & 100 & $0,5 \times 10^{5}$ & $0,8 \times 10^{3}$ & $0,5 \times 10^{2}$ \\
Indaiá & 3 & 100 & $1,4 \times 10^{5}$ & $0,5 \times 10^{4}$ & $0,5 \times 10^{3}$ \\
Cocanha & 3 & 100 & $1,6 \times 10^{4}$ & $1,0 \times 10^{4}$ & $0,2 \times 10^{2}$ \\
Tabatinga & 3 & 100 & $1,7 \times 10^{2}$ & $0,5 \times 10^{2}$ & $0,2 \times 10^{2}$ \\
\hline
\end{tabular}

Diferentes fatores como efeitos das marés, descarga de esgoto sanitário, mudança de estação do ano, presença de animais e o número de banhistas têm sido apontados como contribuintes para a sobrevivência e dispersão de micro-or- 
ganismos patogênicos em areia de praia. A sobrevivência de bactérias entéricas na superfície de areia seca pode ser de curta duração devido à ação do meio ambiente. Já a areia úmida enriquecida com matéria orgânica confere ao ambiente condições favoráveis, permitindo um período de sobrevivência maior do que em água do mar (WHO, 2003). Noble et al. (2004) e Beversdorf et al. (2007) afirmaram que fatores como a umidade, temperatura, raios UV e a concentração de carbono orgânico dissolvido são alguns dos fatores que afetam a viabilidade de micro-organismos na areia.

Constatou-se presença de coliformes termotolerantes com confirmação de Escherichia coli (Tabela 2). E. coli é uma bactéria que tem sido amplamente utilizada como indicador de contaminação de origem fecal. O babitat natural e principal reservatório de $E$. coli é o trato intestinal do homem e outros animais homeotérmicos, sendo, portanto, abundante em esgotos, efluentes, águas naturais e solos que tenham recebido contaminação fecal recente. Sua presença indica a possibilidade da existência de outros micro-organismos, entre estes, aqueles patogênicos ao homem (ABDALLAH et al., 2005; SATO et al., 2005; VALDEZ; GROSBELLI, 2012; ANDRAUS et al., 2014).

Stewart et al. (2008) afirmaram que além das fontes pontuais de contaminação devem ser consideradas as fontes difusas, que são disseminadas e dificilmente reconhecíveis. A carga microbiana de fontes difusas é grande, encontrada no escoamento da área urbana e áreas rurais, vazamentos de sistemas de limpeza biológicos e sistemas de drenagem, as descargas a partir de barcos e deposição atmosférica de aerossóis.

A concentração de coliformes totais e termotolerantes e de $E$. coli na areia das diferentes praias foi variável, sendo maior nas praias Porto Novo, Centro, Martins de Sá, Indaiá e Cocanha. No entanto não existem normativas que estabelecem índices máximos destes micro-organismos na areia. Os parâmetros estabelecidos nas resoluções Conama 20/86 (índice máximo para coliformes totais $5000 \mathrm{NMP} / 100 \mathrm{~mL}$ ) e resolução Conama 274/00 (índices máximos para coliformes termotolerantes 1000 NMP/100 mL) para a água (BRASIL, 1986; 2001), havendo ausência de parâmetros específicos para a areia.

Na Tabela 2 estão apresentados os resultados de resistência e susceptibilidade a antimicrobianos de cepas de $E$. col $i$ isoladas na areia. Verificou-se multirre- 
sistência aos antimicrobianos nas cepas de isoladas E. coli nas praias Porto Novo, Centro, Indaiá, Cocanha e Tabatinga. Cepas de Escherichia coli diarreiogênicas podem causar infecções entéricas em humanos e incluem seis categorias diferentes de acordo com fatores de virulência. A exposição humana à água contaminada constitui um importante mecanismo para a transmissão de patógenos gastrointestinais (OLIVEIRA et al., 2012).

Tabela 2. Susceptibilidade (S), susceptibilidade intermediária (I), resistência (R) e índice de resistência múltipla (IRMA) a diferentes classes de antimicrobianos de cepas de Escherichia coli, isoladas de areia de praias do município de Caraguatatuba (SP)

\begin{tabular}{|c|c|c|c|c|c|c|c|c|c|c|c|c|c|c|c|c|c|}
\hline \multirow{2}{*}{ Amostras } & \multicolumn{17}{|c|}{ Antimicrobianos } \\
\hline & $\mathrm{AM}$ & AT & $\mathrm{AP}$ & $\mathrm{CF}$ & $\mathrm{CZ}$ & $\mathrm{CL}$ & $\mathrm{CX}$ & $\mathrm{CO}$ & $\mathrm{CA}$ & $\mathrm{CP}$ & CR & $\mathrm{CI}$ & $\mathrm{CL}$ & CR & ER & $\mathrm{TE}$ & IRMA \\
\hline Prainha & $S$ & $S$ & $S$ & $\mathrm{R}$ & $\mathrm{R}$ & $S$ & $S$ & $S$ & $S$ & $S$ & I & I & $S$ & $S$ & $S$ & $\mathrm{R}$ & 0,18 \\
\hline Porto Novo & S & $\mathrm{R}$ & S & $\mathrm{R}$ & S & $S$ & $\mathrm{R}$ & $S$ & $S$ & $S$ & $S$ & $S$ & $S$ & I & $\mathrm{S}$ & $\mathrm{R}$ & 0,25 \\
\hline $\begin{array}{l}\text { Martins de } \\
\text { Sá }\end{array}$ & S & $\mathrm{S}$ & S & $S$ & $\mathrm{R}$ & $S$ & I & $S$ & $\mathrm{R}$ & $S$ & $S$ & $S$ & I & I & $\mathrm{S}$ & $\mathrm{R}$ & 0,18 \\
\hline Centro & $\mathrm{R}$ & $\mathrm{S}$ & S & $\mathrm{R}$ & S & $S$ & $\mathrm{R}$ & $S$ & $\mathrm{R}$ & $S$ & $S$ & $S$ & $S$ & $S$ & $\mathrm{~S}$ & $S$ & 0,25 \\
\hline Indaiá & S & $\mathrm{S}$ & S & $S$ & $\mathrm{R}$ & $S$ & I & $\mathrm{R}$ & I & $S$ & $S$ & $S$ & $\mathrm{R}$ & $\mathrm{R}$ & $\mathrm{R}$ & $\mathrm{R}$ & 0,37 \\
\hline Cocanha & $\mathrm{R}$ & $\mathrm{R}$ & $S$ & $\mathrm{R}$ & $\mathrm{R}$ & $S$ & $S$ & $S$ & $S$ & $S$ & $\mathrm{R}$ & $S$ & $S$ & $\mathrm{R}$ & $S$ & $S$ & 0,37 \\
\hline Tabatinga & $S$ & $S$ & $S$ & $\mathrm{R}$ & $S$ & $\mathrm{R}$ & $\mathrm{R}$ & $S$ & $S$ & I & I & $S$ & $S$ & $S$ & $S$ & $\mathrm{R}$ & 0,25 \\
\hline
\end{tabular}

$\mathrm{AM}=$ amicacina, $\mathrm{AT}=$ aztreonam, $\mathrm{AP}=$ ampicilina, $\mathrm{CF}=$ cefaclor, $\mathrm{CZ}=$ Cefazolina, $\mathrm{CL}=$ cefalotina, $\mathrm{CX}=$ cefotaxime, $\mathrm{CO}=$ cefoxitina, $\mathrm{CA}=$ ceftazidima, $\mathrm{CP}=$ cefepime, $\mathrm{CR}=$ ceftriaxona, $\mathrm{CI}$ $=$ ciprofloxacina, $\mathrm{CL}=$ clindamicina, $\mathrm{CR}=$ cloranfenicol, $\mathrm{ER}=$ eritromicina, $\mathrm{TE}=$ tetraciclina .

Inúmeros fatores podem estar envolvidos para o surgimento de cepas resistentes no ambiente, tais com saneamento insuficiente, uso indiscriminado de antibióticos e falta de sistemas de esgotos bem geridos (OZGUMUS et al., 2008). Coliformes termotolerantes resistentes aos antibióticos canamicina, ácido nalidíxico, tetraciclina e trimetoprim têm sido isolados de duas amostras de fezes de seres humanos e água potável tratada na Índia (PATHAK; GOPAL, 2008). E. coli com altos níveis de resistência à ampicilina, trimetoprim/sulfamethoxazole, gentamicina e tetraciclina foram isolados de fontes de água potável na Jordânia (SHEHABI et al., 2006). Na presente pesquisa foram isoladas cepas de $E$. coli multirresistentes a diferentes antibióticos como apresentado na Tabela 2.

Velonakis et al. (2014) salientam a necessidade de estudos epidemiológicos 
em praias com poluição e correlação com as bacterias indicadoras fecais (FIB). A ausência das FIB nem sempre exclui a presença de outros micro-organismos patógenos em amostras de água do mar. No entanto, há possibilidade de alguns desses micro-organismos provocar infecções para usuários da praia e a real extensão da sua ameaça à saúde pública permanece desconhecida.

\section{CONCLUSÃO}

Foram detectados coliformes totais e termotolerantes e Escherichia coli na areia de todas as praias avaliadas do Município de Caraguatatuba (SP). Concentrações elevadas foram detectadas nas praias Porto Novo, Centro, Martins de Sá, Indaiá e Cocanha. As cepas de Esecherichia coli isoladas das praias de Porto Novo, Centro, Indaiá, Cocanha e Tabatinga apresentaram resistência e multirresistência a alguns antimicrobianos testados.

\section{REFERÊNCIAS}

ABDALLAH, S. A.; ELMANAMA, A. A.; FAHD, M. I.; AFIFI, S. Microbiological Beach Sand Quality in the Gaza Strip in Comparison to Seawater. Polish Journal of Environmental Studies, v. 14, n. 6, p. 841-850, 2005.

ANDRAUS, S.; PIMENTEL, I. C.; DIONÍSIO, J. A. Microbiological monitoring of seawater and sand of beaches Matinhos, Caiobá e Guaratuba-PR, Brazil. Estudios de Biologia Ambiente e Diversidade, v. 36, n. 86, p. 43-55, 2014.

BEVERSDORF, L. J.; BORNSTEIN-FORST, S. M.; MCLELLAN, S. L. The potential for beach sand to serve as a reservoir for Escherichia coli and the physical influences on cell die-off. Journal of Applied Microbiolog y v. 102, p. 1372-1381, 2007.

BRASIL. Conama - Conselho Nacional do Meio Ambiente. Resolução no 20 de 18 de Junho de 1986. Dispõe sobre a classificação das águas, doces, salobras e salinas do Território Nacional. Diário Oficial da União, Brasília, p. 11356-113561, 30 jul. 1986.

BRASIL. Conama - Conselho Nacional do Meio Ambiente. Resolução nº 274 de 29 de 
Novembro de 2000. Revoga os artigos 26 a 34 da Resolução no 20/86 (revogada pela Resolução $\left.n^{0} 357 / 05\right)$ e define os critérios de balneabilidade em águas brasileiras. Diário Oficial da União, Brasília, v. 18, seção 1, p. 70-71, 25 jan. 2001.

EATON, A. D.; FRANSON, M. A. H. Standard methods for the examination of water and wastewater. $21^{\text {nd }}$ ed. Washington: APHA; AWWA; WEF, 2005, 1200p.

ELMANAMA, A. A.; FAHD, M. I.; AFIFI, S.; ABDALLAH, S.; BAHR, S. Microbiological beach sand quality in Gaza Strip in comparison to seawater quality. Environmental Research, v. 99, n. 1, p. 1-10, 2005.

CARDOSO-DE-OLIVEIRA, A. J. F.; PINHATA, J. M. W. Antimicrobial resistance and species composition of Enterococcus spp. isolated fromwaters and sands of marine recreational beaches in Southeastern Brazil. Water Research, v. 42, p. 2242-2250, 2008.

CETESB. Coliformes Termotolerantes/2008. Disponível em: <http://www.cetesb. sp.gov.br/userfiles/file/agua/aguassuperficiais/aguasinteriores/variaveis/aguas/variaveis_microbiologicas/coliformes_termotolerantes.pdf > . Acesso em: 19 maio. 2015.

CLSI-Clinical and Laboratory Standards Institute. Publication M100-S23 Suggested Grouping of US-FDA Approved Antimicrobial Agents That Should Be Considered for Routine Testing and Reporting on Non fastidious Organisms by Clinical Laboratories, 2013.

HALLIDAY, E.; MCLELLAN, S. L.; AMARAL-ZETTLER, L. A.; MITCHELL, L. Comparison of bacterial communities in sands and water at beaches with bacterial water quality violations. Plos One, v. 9, n. 3, 2014.

KRUMPERMAN, P. H. Multiple antibiotic resistance indexing of Escherichia coli to identify high-risk sources of fecal contamination of foods. Applied Environmental Microbioliology, v. 46, p. 165-170, 1983.

NOBLE, R. T.; LEE, I. M.; SHIFF, K. C. Inactivation of indicator microorganisms from various sources of faecal contamination in seawater and freshwater. Journal of Applied Microbiology, v. 96, n. 3, p. 464-472, 2004.

OLIVEIRA, K. W.; GOMES, F. C. O.; BENKO, G.; PIMENTA, R. S.; MAGALHÃES, P. P.; 
MENDES, E. N.; MORAIS, P. B. Antimicrobial resistance profiles of diarrheagenic Escherichia coli strains isolated from bathing waters of the Lajeado reservoir in Tocantins, Brazil. Revista Ambiente \& Água, v. 7, n. 2, p. 30-41, 2012.

OZGUMUS, O. B.; CELIK-SEVIM, E.; ALPAY-KARAOGLU, S.; SANDALLI, C.; SEVIM, A. Molecular characterization of antibiotic resistant Escherichia coli strains isolated from tap and spring waters in a coastal region in Turkey. Journal of Microbiology, v. 45 , n. 5 , p. 379-387, 2007.

PINTO, A. B.; OLIVEIRA, A. J. F. C. Diversidade de microrganismos indicadores utilizados na avaliação da contaminação fecal de areias de praias recreacionais marinhas: estado atual do conhecimento e perspectivas. São Paulo: O Mundo da Saúde, 2011.

SHEHABI, A. A.; ODEH, J. F.; FAYYAD, M. Characterization of antimicrobial resistance and class 1 integrons found in Escherichia coli isolates from human stools and drinking water sources in Jordan. Journal of Chemotherapy, v. 18, n. 5, p. 468-472, 2006.

PATHAK, S. P.; GOPAL, K. Prevalence of bacterial contamination with antibiotic-resistant and enterotoxigenic fecal coliforms in treated drinking water. Journal of Toxicology and Environmental Health, v. 71, n. 7, p. 427-433, 2008.

SATO, M. I. Z.; BARI, M. D.; LAMPARELLI, C. C.; TRUZZI, A. C.; COELHO, M. C. L. S.; HACHICH, E. M. Sanitary quality of sands from marine recreational beaches of São Paulo. Brazilian Journal of Microbioloy, v. 36, n. 4, p. 321-326, 2005.

SHIBATA, T.; SOLO-GABIELE, H. M. Quantitative Microbial Risk Assessment of Human Illness from Exposure to Marine Beach Sand. Environmental Science \& Technology, v. 46, p. 2799-2805, 2012.

STEWART, J. R.; GAST, R. J.; FUJIOKA, R. S.; SOLO-GABRIELE, H. M.; MESCHKE, J. S.; AMARAL-ZETTLER, L. A. The coastal environment and human health: microbial indicators, pathogens, sentinels and reservoirs. Environmental Health; v. 7 (Supple 2): S3, p. 1-14, 2008. 
VALDEZ, R. H.; GROSBELLI, P. P. Análise microbiológica de areias de praças públicas da cidade de Palmas (PR). Ambiência - Revista do Setor de Ciências Agrárias e Ambientais, v. 8, n. 3, p. 833-844, 2012.

VASCONCELLOS, F. C.; IGANCI, J. R. V.; RIBEIRO, G. A. Qualidade microbiológica da água do Rio São Lourenço, São Lourenço do Sul, Rio Grande do Sul. Arquivos do Instituto Biológico, v. 73, n. 2, p. 177-181, 2006.

VELONAKIS, E.; DIMITRIADI, D.; PAPADOGIANNAKIS, E.; VATOPOULOS, A. Present status of effect of microorganisms from sand beach on public health. Journal of Coastal Life Medicine, v. 2, n. 9, p. 746-756, 2014.

WHO - WORLD HEALTH ORGANIZATION. Regional Office for Europe. Development of WHO Guidelines for Safe Recreational Water Environments. WHO, 2003. Disponível em: < http://www.euro.who.int/document/e58484.pdf>. Acesso em: 05 mar. 2015.

Recebido em: 26/08/2016 Aceito em: 14/10/2017 